\title{
Marine Robotics Competitions: a Survey
}

\author{
Fausto Ferreira ${ }^{1} \cdot$ Gabriele Ferri $^{1}$ (D)
}

Published online: 1 October 2020

(C) Springer Nature Switzerland AG 2020

\begin{abstract}
Purpose of Review Starting from late 1990s, new marine robotics competitions have spread around the world. Today, the importance of competitions for both educational purposes and technological innovation is widely recognised by the community. In this paper, we present an overview of this kind of challenges, using the most representative events to describe common trends and unique aspects.

Recent Findings Recently, competitions have been in a rapid evolution. Trends are the increasing popularity of Grand Challenges, the push for autonomous decision-making, the introduction of multi-domain cooperation and the birth of virtual competitions. More attention has been given to the scientific aspects, stressing the benchmarking/metrological perspective. Finally, forums and workshops are currently seen as a way to complement competitions and to create a community of interest. Summary Marine robotics competitions enable junior and expert teams to acquire experience in realistic environments. Virtual competitions can help in this aspect. They are useful for preparing team participation in the physical events, especially for open sea competitions. They allow teams to focus on advancing vehicle autonomy. Furthermore, they are important to widen the marine community attracting other robotics and AI experts.
\end{abstract}

Keywords Marine robotics $\cdot$ AUVs $\cdot$ ASVs $\cdot$ ROVs $\cdot$ Multi-domain robotics $\cdot$ Educational robotics

\section{Introduction}

In the last decades, robotics competitions around the world have played a considerable role in the education and formation of new generations of scientists and engineers [1-5]. Robotics competitions' main objectives are to push the state of the art in specific topics of interest $[1,3,4]$ and to be the perfect complement for students to academic classes [2]. Competitions offer the opportunity to put the skills learned on books in practice in realistic scenarios, challenging the soft skills of the teams of students such as managerial capabilities required

This article belongs to the Topical Collection on Underwater Robotics

Gabriele Ferri

Gabriele.Ferri@cmre.nato.int

Fausto Ferreira

Fausto.Ferreira@cmre.nato.int

1 NATO Science and Technology Organization, Centre for Maritime Research and Experimentation (CMRE), Viale San Bartolomeo 400, 19126 La Spezia, Italy to organise the teamwork and to handle the robot preparation under stress conditions and in the short available time.

For these reasons, robotics competitions are spreading geographically and in scope [6]. The marine field is not an exception to this rule. Since the inception of the first underwater robotics competition in the 1990s (RoboSub [7] held in Panama City, Florida and since 2002 in San Diego, California), others were born around the world, each one with different objectives and specificities. There are now marine robotics competitions covering surface vehicles and underwater vehicles, both autonomous and remotely operated [8-32]. More recently, virtual [31] and multi-domain competitions [23••, 30] started to push research teams to test robotics solutions in real-life challenges. The geographical spread goes from the USA to Asia and Europe with plans to expand to South America. At the same time, the goal of current marine robotics competitions can vary from Grand Challenges to educational, and, more recently, increased attention has been put to the scientific perspective of the challenges using the events as a platform for benchmarking and metrological evaluation [23••, 30, 32-34]. In this article, we will present an overview of the current status of marine robotics competitions, characterising each event according to its target participants, goals, robot type and other characteristics. 
Oceans are still a challenging scenario for robot operations. Lack of possibility to use gasoline engines underwater (limited endurance), engineering challenges (e.g. launch/recovery operations) and limitations of underwater propagation of electromagnetic waves (lack of Global Navigation Satellite System (GNSS) and Radio Frequency (RF) communications) make the execution and management of robot missions difficult. Many issues for robots have still to be fully solved, such as autonomous navigation, underwater sensing (sonar and not vision is the primary sensing modality) and persistent autonomy.

Marine robotics competitions have been recognised useful for pushing the state of the art in all of these topics. Recent marine robotics competitions have proposed so-called Grand Challenges. In a Grand Challenge, a complex task not currently solved by state-of-the-art robots has to be tackled. One example is the Shell Ocean Discovery XPRIZE that with a 7 million dollars prize money demanded international teams to create robotics solutions to map the seafloor quickly and with high resolution $[28,29 \bullet \cdot$. Results of the competition demonstrated its benefits in advancing the current technological solutions.

The described difficulties increase the importance of the educational role of marine robotics competitions $[35,36]$. Competitions allow students and less expert research teams to start or to acquire experience in the marine domain [37]. They also stimulate teams with realistic challenges, such as operating a vehicle in the water for extended periods. Teams have to consider practical issues such as the influence of salinity for acoustic measures, waves, tides, turbidity and light condition changes, aspects usually not faced during classes at the university. To be successful in such competitions, good teamwork is necessary, especially in teams that are typically multi-disciplinary. Participants learn not only technical but also the so-called soft skills, including presentation skills, management, dissemination and fundraising. Besides this educational role, competitions can address one of the main difficulties of marine robotics research groups around the world: the access to sea/real-life conditions. Many universities and research centres have only small pools or tanks. While some competitions take place in swimming pools (typically those targeting high school participants), others take place in ponds, lakes or at sea where the conditions are more realistic and challenging [9-11, 15, 16, 23••, 27-30, 32]. By giving this opportunity to teams, competitions allow and force them to test their algorithms in real-world settings.

Finally, competitions can also play a role in innovation and technology transfer. In more than one case, teams and research groups participating in competitions matured and formed in some cases companies $[38,39]$ or built their own vehicles after experiencing for the first time marine robotics through a competition.

RoboSub paved the way to other competitions born around the world that followed, at least initially, its path both in terms of tasks and target participants. Over the past few years, new trends have been observed in the main events. Currently, the most popular competitions, while having some common tasks and elements, differ considerably in their goals, target participants, required autonomy level and domain (surface, underwater, multi-domain). In order to address the panoply and variety of marine robotics competitions around the world, the Marine Autonomous Systems Competition Committee (MASC2) committee has been formed with the objective to harmonise the different competitions currently present. MASC2 was created by the Oceanic Engineering Society (OES), one of the professional societies operating under the International Electrical and Electronics Engineering (IEEE) banner, in collaboration with the Office of Naval Research (ONR). Originally named Autonomous Marine Vehicle Student Competition (AMVSC) International Coordinating Committee [40], this committee was formed in March 2017, and it seeks to establish common elements of autonomy across the competitions. The panel renamed AMVSC to Marine Autonomous Systems Competition Committee (MASC2) in an effort to better capture aerial and surface vehicles in vertical as well as in horizontally integrated systems.

The rest of the paper is organised as follows. "Marine Robotics Competitions in the World" gives an overview of the marine robotics competitions around the world, classifying them according to several parameters. "Selected Cases: RoboSub, SAUC-E/euRathlon/ERL, SAUVC, RobotX" details some of the more relevant events existent in each continent. "Conclusions" concludes the article with some remarks on future directions.

\section{Marine Robotics Competitions in the World}

The most relevant marine robotics competitions are reported in Table 1 with their main characteristics. Seven parameters are considered for each event. The competitions are ordered by the year of their first edition, from the first competition (RoboSub [7]) to the latest (METRICS [32]). As can be seen in Table 1, after the first marine robotics event started in 1997, most of the competitions started in the mid- to late 2000s. The geographical spread covers the whole world with a robust presence in the USA, Europe and Asia. It is worth to notice that some competitions have local and regional tournaments spread in different continents (including Africa, Oceania and South America) in preparation for the International final tournament. This is the case of Marine Advanced Technology Education (MATE) Remotely Operated Vehicle (ROV) competition [8] and SeaPerch [17-19]. The MicroTransat Challenge [9] joins two continents as teams can either cross the Atlantic from North America to Europe or vice-versa. Some challenges take place in the same country (and place) every year while others rotate. The majority of competitions 
Table 1 Summary of the most representative competitions in marine robotics

\begin{tabular}{|c|c|c|c|c|c|c|c|}
\hline Name & Country & Years & Domain & $\begin{array}{l}\text { Autonomy in } \\
\text { the marine } \\
\text { scenario }\end{array}$ & $\begin{array}{l}\text { Participant } \\
\text { target }\end{array}$ & Environment & $\begin{array}{l}\text { Main } \\
\text { objective }\end{array}$ \\
\hline RoboSub [7] & USA & 1997- & Underwater & AUV & $\begin{array}{l}\text { Student (high } \\
\text { school and } \\
\text { university) }\end{array}$ & $\begin{array}{l}\text { Pond } \\
\text { (anechoic } \\
\text { pool) }\end{array}$ & Educational \\
\hline MATE ROV [8] & $\begin{array}{l}\text { World- } \\
\text { wide/U- } \\
\text { SA } \\
\text { (final) }\end{array}$ & 2001- & Underwater & ROV & $\begin{array}{l}\text { Student (from } \\
\text { elementary } \\
\text { to } \\
\text { university) }\end{array}$ & $\begin{array}{l}\text { Swimming } \\
\text { pool }\end{array}$ & Educational \\
\hline $\begin{array}{l}\text { Microtransat } \\
\text { Challenge [9] }\end{array}$ & $\begin{array}{l}\text { North } \\
\text { Atlantic }\end{array}$ & $\begin{array}{l}\text { 2006-2007, } \\
2010-\end{array}$ & Surface & ASV & $\begin{array}{l}\text { Any } \\
\text { organisa- } \\
\text { tion }\end{array}$ & Open sea & Grand Challenge \\
\hline SailBot [10] & $\begin{array}{l}\text { North } \\
\text { America } \\
\text { (USA } \\
\text { and } \\
\text { Canada) }\end{array}$ & $\begin{array}{l}2006 \\
2008-\end{array}$ & Surface & ASV & $\begin{array}{l}\text { Any } \\
\text { organisa- } \\
\text { tion }\end{array}$ & Lake & $\begin{array}{l}\text { Educational/preparation } \\
\text { for MicroTransat } \\
\text { Challenge or World } \\
\text { Robotics Sailing } \\
\text { Championship }\end{array}$ \\
\hline SAUC-E [11] & $\begin{array}{l}\text { Europe/- } \\
\text { Italy } \\
\text { (since } \\
2010 \text { ) }\end{array}$ & $2006-$ & Underwater/surface & AUV/ASV & $\begin{array}{r}\text { University } \\
\text { students }\end{array}$ & $\begin{array}{l}\text { Open sea } \\
\text { (protected } \\
\text { harbour) }\end{array}$ & Educational \\
\hline $\begin{array}{l}\text { Underwater Robot } \\
\text { Convention/Competit- } \\
\text { ion }[12,13]\end{array}$ & Japan & 2006- & Underwater & AUV/ROV & $\begin{array}{r}\text { Student (high } \\
\text { school and } \\
\text { university) }\end{array}$ & $\begin{array}{l}\text { Swimming } \\
\text { pool }\end{array}$ & Educational \\
\hline RoboBoat [14] & USA & $2008-$ & Surface & ASV & $\begin{array}{r}\text { Student (high } \\
\text { school and } \\
\text { university) }\end{array}$ & Pond & Educational \\
\hline $\begin{array}{l}\text { World Robotics Sailing } \\
\text { Championship }[15,16]\end{array}$ & Worldwide & 2008 & Surface & ASV & $\begin{array}{l}\text { Any } \\
\text { organisa- } \\
\text { tion }\end{array}$ & Open sea & Grand Challenge \\
\hline SeaPerch [17-19] & $\begin{array}{l}\text { Worlwi- } \\
\text { de/USA } \\
\text { (final) }\end{array}$ & $2008-$ & Underwater & ROV & $\begin{array}{l}\text { K-12 } \\
\text { education }\end{array}$ & $\begin{array}{l}\text { Swimming } \\
\text { pool }\end{array}$ & Educational \\
\hline $\begin{array}{l}\text { Students Autonomous } \\
\text { Underwater Vehicle } \\
\text { (SAVe) }[20-22]\end{array}$ & India & 2011- & Underwater & AUV & $\begin{array}{r}\text { University } \\
\text { students }\end{array}$ & $\begin{array}{l}\text { Swimming } \\
\text { pool }\end{array}$ & Educational \\
\hline euRathlon $[23 \bullet \bullet, 47]$ & $\begin{array}{l}\text { Europe/- } \\
\text { Italy }\end{array}$ & 2013-2015 & $\begin{array}{l}\text { Multi-domain (sea, } \\
\text { air and land) }\end{array}$ & $\begin{array}{l}\text { AUV/ASV } \\
\text { and ROV } \\
\text { (only for } \\
\text { manipula- } \\
\text { tion) }\end{array}$ & $\begin{array}{l}\text { University } \\
\text { (including } \\
\text { non-- } \\
\text { students) } \\
\text { and } \\
\text { Industry }\end{array}$ & $\begin{array}{l}\text { Open sea } \\
\text { (protected } \\
\text { harbour) }\end{array}$ & Grand Challenge \\
\hline $\begin{array}{l}\text { Oceanology International } \\
\text { (OI) China } \\
\text { Underwater Robot } \\
\text { Competition [24] }\end{array}$ & China & 2013-2017 & Underwater & ROV & $\begin{array}{r}\text { University } \\
\text { students }\end{array}$ & $\begin{array}{l}\text { Swimming } \\
\text { pool }\end{array}$ & Educational \\
\hline SAUVC $[25,26]$ & Singapore & 2013- & Underwater & AUV & $\begin{array}{r}\text { Student (high } \\
\text { school and } \\
\text { university) }\end{array}$ & $\begin{array}{l}\text { Swimming } \\
\text { pool }\end{array}$ & Educational \\
\hline $\begin{array}{r}\text { Maritime RobotX } \\
\text { Challenge [27] }\end{array}$ & $\begin{array}{l}\text { USA/Si- } \\
\text { ngapore }\end{array}$ & 2014- & Surface & ASV & $\begin{array}{l}\text { University } \\
\text { students }\end{array}$ & Open sea & Grand Challenge \\
\hline $\begin{array}{c}\text { Shell Ocean Discovery } \\
\text { XPRIZE }[28,29 \bullet \bullet\end{array}$ & $\begin{array}{l}\text { Greece and } \\
\quad \text { Puerto } \\
\text { Rico }\end{array}$ & 2015-2019 & Underwater & $\begin{array}{l}\text { AUV, ASV } \\
\text { and UAV }\end{array}$ & $\begin{array}{l}\text { Any } \\
\text { organisa- } \\
\text { tion }\end{array}$ & Open sea & Grand Challenge \\
\hline $\begin{array}{l}\text { European Robotics } \\
\text { League Emergency } \\
\text { [30] }\end{array}$ & Europe & 2017- & $\begin{array}{l}\text { Multi-domain (sea, } \\
\text { air and land) }\end{array}$ & $\begin{array}{l}\text { AUV/ASV } \\
\text { and ROV } \\
\text { (only for }\end{array}$ & $\begin{array}{l}\text { University } \\
\quad \text { (including } \\
\text { non-- } \\
\text { students) }\end{array}$ & $\begin{array}{l}\text { Open sea } \\
\text { (protected } \\
\text { harbour) }\end{array}$ & Benchmarking \\
\hline
\end{tabular}


Table 1 (continued)

\begin{tabular}{|c|c|c|c|c|c|c|c|}
\hline Name & Country & Years & Domain & $\begin{array}{l}\text { Autonomy in } \\
\text { the marine } \\
\text { scenario }\end{array}$ & $\begin{array}{l}\text { Participant } \\
\text { target }\end{array}$ & Environment & $\begin{array}{l}\text { Main } \\
\text { objective }\end{array}$ \\
\hline & & & & $\begin{array}{l}\text { manipula- } \\
\text { tion) }\end{array}$ & $\begin{array}{l}\text { and } \\
\text { Industry }\end{array}$ & & \\
\hline Virtual RobotX [31] & Worldwide & 2019- & Surface & ASV & $\begin{array}{r}\text { University } \\
\text { students }\end{array}$ & Online & $\begin{array}{l}\text { Prepare teams for } \\
\text { real-world challenge }\end{array}$ \\
\hline METRICS [32] & Europe & $2020-$ & Underwater & $\begin{array}{l}\text { AUV and } \\
\text { ROV (only } \\
\text { for } \\
\text { manipula- } \\
\text { tion) }\end{array}$ & $\begin{array}{l}\text { University } \\
\quad \text { (including } \\
\text { non-- } \\
\text { students) } \\
\text { and } \\
\text { Industry }\end{array}$ & $\begin{array}{l}\text { Open sea } \\
\text { (protected } \\
\text { harbour) }\end{array}$ & $\begin{array}{r}\text { Metrological } \\
\text { evaluation }\end{array}$ \\
\hline
\end{tabular}

address the underwater domain although surface competitions have become more popular in recent years. It is important to remark that in Europe competitions evolved towards multidomain, including all the domains (sea, land and air) and robots of different types. Autonomous Underwater Vehicles (AUVs) and Autonomous Surface Vehicles (ASVs) participated in these competitions together with Unmanned Aerial Vehicles (UAVs) and Unmanned Ground Vehicles (UGVs). In some cases, ASVs and UAVs act as communication relays between AUVs and UGVs (e.g. euRathlon 2015 Grand Challenge [23.•] and European Robotics League (ERL) Emergency 2017 [41]) introducing multi-domain cooperation in the maritime domain.

In other communities, virtual challenges have been used for presenting a simulation environment to the teams as preparation or as qualification [42] to the physical challenge [1]. Virtual challenges have recently been proposed also in the marine community. The first example of such competitions is the Virtual RobotX [31]. It is an online competition based on the scenarios of the RobotX Challenge, set in a sheltered seawater basin and involving autonomous surface vehicles. Tasks include autonomous navigation (including station-keeping and obstacle avoidance capabilities), perception (optical and acoustic) and adaptive mission planning [43••]. The Virtual RobotX aims at preparing teams for the (physical) RobotX Challenge [27], at the same time attracting new potential participants. Virtual competitions are an effective way for setting-up and evaluating robot software whenever complex logistics hampers the testing of the robot hardware. Indeed, the size of the vehicles used at the RobotX Challenge (5$\mathrm{m}$ long and 2.5-m wide) prevents teams from testing them effectively in pools and makes it difficult to validate them in the open sea. A virtual competition based in the same scenario can help teams to prepare and test their algorithms in simulation before the real challenge. In a virtual environment, judging is simpler and fairer, since subjectivity is reduced, if not eliminated. More importantly, all the environmental factors in the simulation are controlled, which enables all teams to compete in the same conditions. The results produced by the different teams are easily comparable. This is usually not possible in a physical competition, where different wind, tide and wave features influence teams' performance.

The possibility to test the team algorithms in a controllable and repetitive way suggested using a similar approach in the new Metrological Evaluation and Testing of Robots in International CompetitionS (METRICS) project [32]. As its name shows, METRICS goes a step beyond benchmarking and aims to perform metrological evaluation through competitions. It does that by a series of field evaluation campaigns (physical competitions-for the marine domain underwater robots will be challenged with inspection and maintenance tasks) and cascade evaluation campaigns (based on data acquired at the physical competitions and successively annotated). In the field evaluation campaigns, efforts will be made to measure the environmental variables and to provide a fair data comparison by taking into account the weather conditions in a quantifiable way. On the other hand, the cascade evaluations will be able to test algorithms of the different teams in the same conditions. The cascade evaluations have a two-fold goal. They work as a preparation step for teams to develop their perception and navigation algorithms for the physical competition (like in Virtual RobotX). They are also a way to involve the Artificial Intelligence (AI) community that may not be ready to participate in robotics competitions but can use the collected dataset to develop novel algorithms and possibly participate in future competitions.

In terms of autonomy level, most underwater competitions are dedicated to AUVs in which an underwater robot performs a given mission with no intervention of a human operator. ROVs are more popular in competitions targeted at preuniversity students (of all ages). ROVs are robots commanded via a cable from a control station. This simplifies for younger participants the control of the vehicle during the competition.

Fully remote control (joystick) is generally allowed only for safety reasons when surface robots are employed. 
Exceptions exist for some of the challenges within SailBot [10] competition. In some competitions such as euRathlon 2015 Grand Challenge [23••] or in the ERL Emergency [30] events, an operator can support the AUV operations transmitting high-level commands (such as start a specific task, move to a waypoint and so on) via an underwater acoustic modem. The purpose is to push teams to acquire experience on underwater communications that are an unavoidable aspect of realworld operations.

There is a strong correlation between the last three columns of Table 1. Most competitions targeted at students (preuniversity) take place in swimming pools and have educational goals. Swimming pools are a perfect venue to run safely a competition involving students. These venues facilitate the judging as well due to the clear water, whereas a competition that targets more expert university students or other professionals, typically, is held in the open sea, and the goal goes beyond educational (either Grand Challenge style, benchmarking or metrological evaluation). This happens in both the underwater and surface domain.

Experience [37] shows the importance for students and for research teams in general to have yearly events. In this way, teams can improve over the years and learn from the unavoidable failures. With the experience acquired from educationaloriented competitions held in simplified environments (i.e. swimming pools), teams can then participate in more complex and professional-oriented challenges, such as Grand Challenge-style competitions.

This path is evident in the surface domain where all types of competitions (virtual, educational and Grand Challenge) are present. For instance, the Sailbot competition (ran at a freshwater lake) acts as preparation for harder challenges such as the World Robotics Sailing Championship (open sea) or the more complex MicroTransat Challenge (Atlantic Ocean). The latter one requires an ASV to cross the Atlantic from North America to Europe or vice-versa. Initially, only robotic sailing boats were allowed, but since 2015 all ASVs are allowed. The MicroTransat Challenge is among the most demanding competitions in marine robotics. Since the first attempt to cross the Atlantic in 2010, only one team in the 2018 edition managed to complete the challenge after 79 days and $12 \mathrm{~h}$ and $5354 \mathrm{~km}$ covered [44].

In "Selected Cases: RoboSub, SAUC-E/euRathlon/ERL, SAUVC, RobotX", we will propose a more detailed overview on some of the most representative marine competitions.

\section{Selected Cases: RoboSub, SAUC-E/euRathlon/ERL, SAUVC, RobotX}

All the competitions presented in this section are represented in the MASC2 committee. More information about these competitions can be found at http://www.autonomousmarinesystems. org/. Although the competitions are different for targets and environment, all of them have in common similar tasks aiming at testing basic robot functionalities. Passing a gate (made of two buoys), navigating in a straight line for a given length, avoiding obstacles and localising an acoustic pinger are present in the events. MASC2 has been working on the harmonisation of the different autonomy tasks. The aim is to design tasks that facilitate robot performance comparison among the different competitions.

\section{RoboSub}

RoboSub [7] was the first AUV competition to start and since its first edition in 1997 has expanded and inspired many others. Co-sponsored by the Office of Naval Research (ONR) and RoboNation (previously named Association for Unmanned Vehicle Systems International (AUVSI) Foundation), since 2002, it takes place at the US Navy Space and Naval Warfare Systems Center Pacific's TRANSDEC Anechoic pool in San Diego, CA (see Fig. 1). RoboSub is currently the most popular competition in the AUV world attracting dozens of teams (up to 500 participants) yearly. Students must constitute at least $75 \%$ of the team, given the educational goal of this competition. Every year, the competition has a different theme, but tasks are similar to previous years. Tasks require a combination of autonomy, perception and basic manipulation. The AUV mission consists of passing a gate, touching a buoy, dropping and retrieving objects and launching a plastic marker inside a target hole. Acoustic pingers guide the robots to the right positions. The pond is around 11-m deep and has a surface of $90 \mathrm{~m} \times 60 \mathrm{~m}$ allowing to divide the arena into four areas and have four teams in the water at the same time. One characteristic of this competition is that performance measures and subjective measures evaluate teams. Subjective measures evaluate the team technical merit, creativity and communication (team video and website), among others. This mode of evaluation is

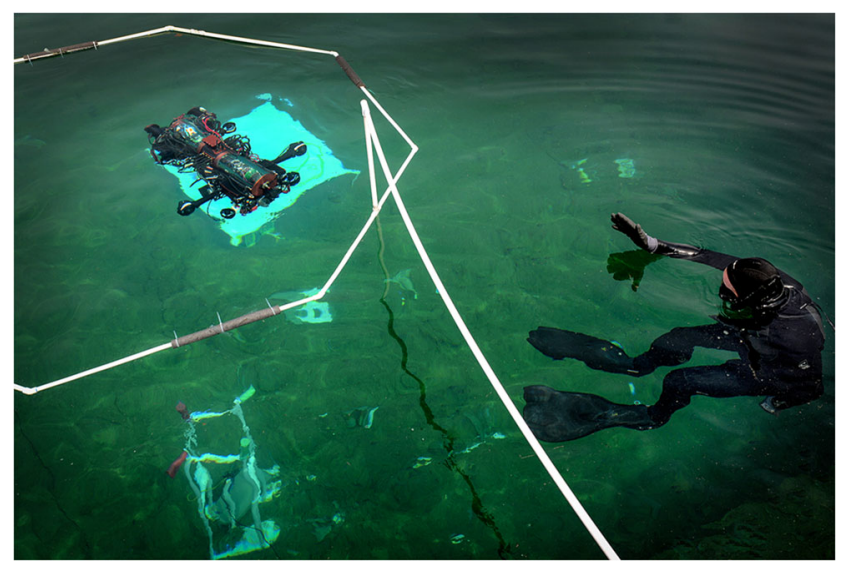

Fig. 1 Arena of RoboSub. (Credit: RoboSub) 
essential in a competition with an educational goal as students have the opportunity to exercise their presentation skills to explain and advertise their design solutions.

\section{SAUC-E, euRathlon and the ERL Emergency}

The Student AUV Challenge-Europe (SAUC-E) [11] was inspired by RoboSub and was the first underwater robotics competition in Europe. As in RoboSub, a minimum of $75 \%$ of team members must be students (in this case, only university level, not high school). A similar scoring system with performance measures and subjective measures is used, since SAUC-E has an educational goal like RoboSub. A significant difference with RoboSub and any other student underwater robotics competition is that SAUC-E takes place in a protected harbour seawater basin. It is considered the most realistic competition of its type (student-based AUV) [45]. The robots operate in seawater and the possible low visibility (see Fig. 2), tides and waves affect teams' performance considerably. Initially rotating between the UK and France, SAUC-E moved in 2010 to Italy to the NATO Undersea Research Centre (NURC) premises, renamed to NATO Science and Technology (STO) Centre for Maritime Research and Experimentation (CMRE) in 2013. Since then, it has been held at CMRE's sea basin in La Spezia, Italy, except in 2015 and 2017 when it was part of wider-scope multi-domain competitions organised in Piombino, Italy.

SAUC-E has been the training ground for several research groups and fostered their growth year after year. Good examples are the University of Girona team that developed for its participation a vehicle, the SPARUS AUV, that was later commercialised by a spin-off company [39]. The University of Florence [46•] and the Team Tomkyle [37] used the SAUC$\mathrm{E}$ arena to improve their vehicles that are today employed in open sea surveys.

Typical SAUC-E tasks include passing through the gate (composed of two submersed buoys), mapping and inspecting an underwater pipeline structure, localising on the seafloor a pinger that emit an acoustic wave and localising/imaging underwater buoys and objects.

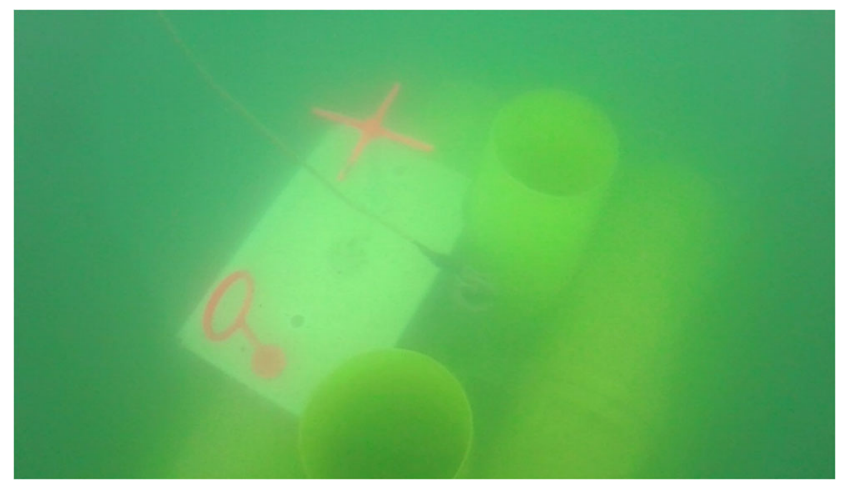

Fig. 2 An example of the low visibility found in the SAUC-E arena
SAUC-E enlarged its scope and included other domains to push teams to work on multi-robot multi-domain cooperation. Since 2012, ASVs were included in the competition. In 2012, AUVs had to track the NURC's ASV. Since 2013, new cooperative tasks between AUVs and ASVs were added to the competition. One important feature is that these cooperative tasks could be achieved by two AUVs from different teams, increasing the potential for collaboration between teams and the fair play spirit.

SAUC-E effort in enlarging the scope of underwater robotics competitions culminated in being one of the roots of the euRathlon EU project [47]. euRathlon had two preliminary competitions (single-domain, land and sea) in preparation to the euRathlon 2015 Grand Challenge [23••]. euRathlon 2015 Grand Challenge was the first competition in the world in which a robotics team composed of cooperative marine, land and aerial vehicles had to operate in a realistic search and rescue scenario inspired by the Fukushima 2011 accident. The competition took place in a dismissed power plant in Piombino, Italy, and its protected harbour as in Fig. 3. Within the marine domain, AUVs competed in a sheltered water basin characterised by extremely reduced visibility (sometimes $<1 \mathrm{~m}$ ). The robots had to survey an area to map a pipeline structure, localise a mannequin (a mock missing worker after the accident), detect underwater objects and close a valve underwater. AUVs could be used as ROVs (tethered) only during the manipulation task only. ASVs were allowed to help AUVs with mapping and localisation and as a communications relay between AUVs and UGVs/UAVs. Being a Grand Challenge, the complexity level was higher compared with a student competition. Both industry and academia teams were allowed to compete. The euRathlon 2015 Grand Challenge practically eliminated all subjective measures as the primary goal was the advancement of the state of the art.

More recently, the ERL Emergency [30] followed the path started by euRathlon 2015 Grand Challenge. Supported by the RoCKEU2 EU project between 2016 and 2018, ERL Emergency 2017 took place in the same scenario as

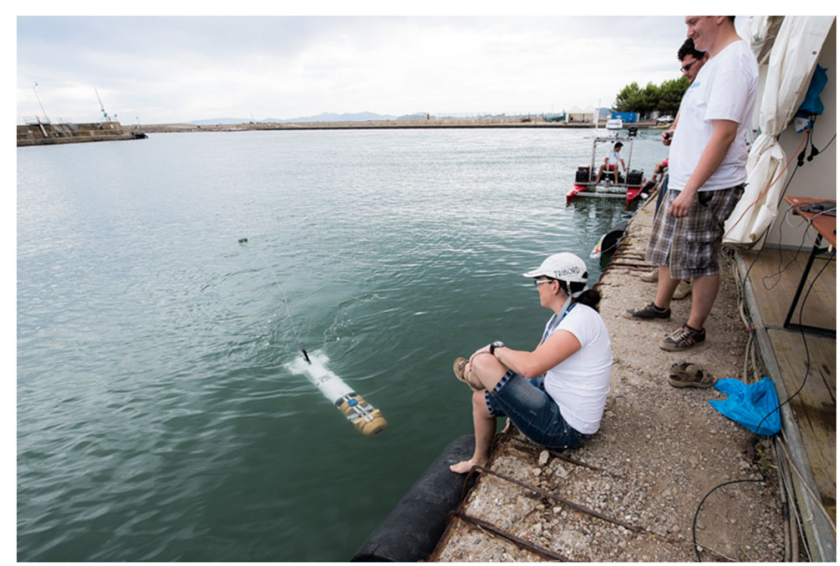

Fig. 3 The large protected harbour of euRathlon 2015 Grand Challenge 
Fig. 4 The WAM-V ASV and the floating pontoon part of the RobotX arena

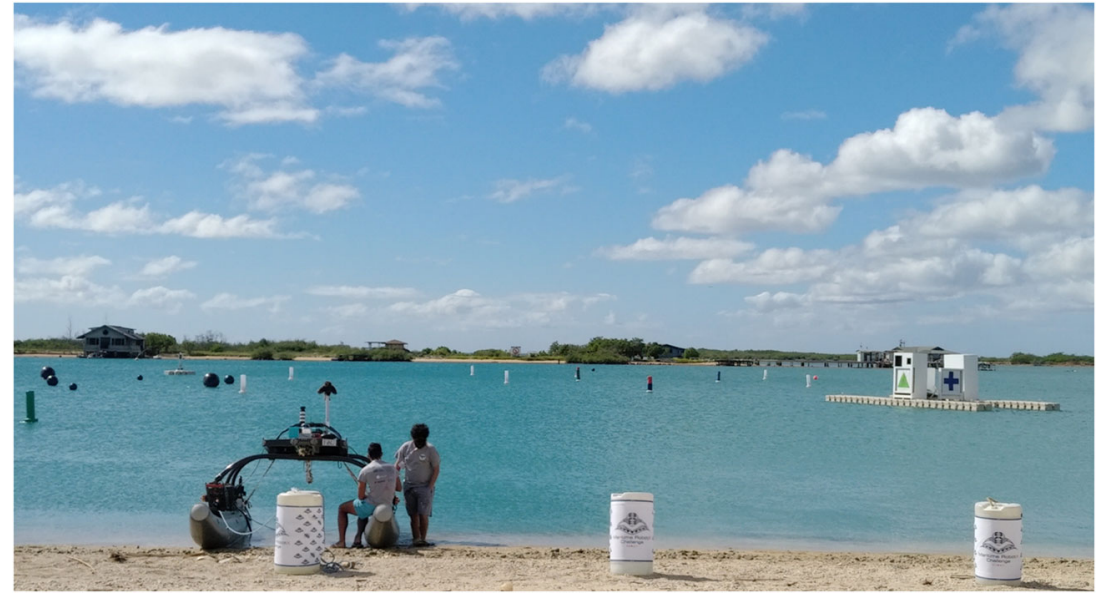

euRathlon 2015 Grand Challenge. For the second time, a competition included all three types of robots (marine, land and aerial). Tasks were modified given the results of previous competitions and the new goal of this competition (benchmarking). Benchmarking the results of an outdoor competition is challenging. In the case of AUVs, the biggest problem is that the position ground truth is hardly available. In ERL Emergency 2017, a Long BaseLine (LBL) solution provided by University of Newcastle/Blueprint Subsea was allowed to track the real-time position of each AUV. This tracking was useful to the judges, especially considering the open sea conditions and murky waters, but a more significant and dedicated effort is needed in the future. ERL Emergency 2018 and 2019 took place in CMRE's basin in La Spezia, Italy. Up to 2018, most of the tasks presented to the teams could be pre-programmed with no need for on-board decisionmaking (except for cooperative tasks with ASVs). However, in ERL Emergency 2019, autonomous decision-making and adaptive mission planning were required. The robots had to detect buoys of different colours. Based on the recognised colour, they had to adapt their mission and perform a different action. The colour recognition proved to be challenging due to the low visibility present in CMRE's sea basin. Nevertheless, it pushed teams to relate their computer vision and machine learning algorithms to a data-driven mission management.

\section{RobotX}

The Maritime RobotX Challenge [27] is a competition held every 2 years (in 2014, 2016 and 2018 so far) that requires surface vessels to accomplish tasks autonomously in a sea course. The competition site is a sheltered seawater basin in Oahu, Hawaii (since 2016), where changing wind and light conditions affect team performance strongly. All participant teams are provided with the same catamaran (a WAM-V [48] ASV, 5-m long and 2.5-wide, shown in Fig. 4). Participants must develop the robot locomotion system (e.g. integrating additional thrusters for docking or station-keeping), and they have to specialise the vehicle adding sensors and actuators.

The catamarans are required to accomplish a sequence of tasks moving inside a large course $(\sim 105 \mathrm{~m} \times 105 \mathrm{~m})$. They are requested to localise an underwater pinger that signals which gate to cross, to navigate in an obstacle field avoiding floating objects, to detect the colour of a light and, according to the identified colour, to perform a different action. Then, robots have to dock at a floating pontoon, shoot a plastic ball inside a target area and deploy an AUV to grab rings positioned underwater.

RobotX tasks require perception (vision and acoustics) to be connected to the robot action (e.g. a different colour triggers a different manoeuvre), forcing teams to develop adaptive mission planning strategies. RobotX Challenge is one of the most logistically complex event to organise (three identical courses were prepared for the teams) and to participate in due to the vehicle size (thus the need for Virtual competitions associated). Typical of RobotX is to provide each team with the same robot. Offering a baseline platform facilitates team participation. At the same time, it provides a way to compare teams' performance for what concerns the navigation-related functionalities.

RoboNation (the organiser of RobotX as well as RoboSub and RoboBoat) has created a virtuous circle for developing the RobotX community. A Forum takes place in between the biannual RobotX Challenges, and gathers judges, previous participants and all relevant stakeholders. The Forum has been crucial to create a community, discuss the feedback from the previous editions and exchange knowledge among the participants and potential participants. The Forum, together with the addition in 2019 of the Virtual RobotX [31] competition, is effective to disseminate the lessons learned from past editions and to help future teams' participation.

Having forums/workshops related to the competition is becoming more and more popular in marine robotics, such as in the Singapore AUV Challenge (SAUVC). 
Fig. 5 The SAUVC Arena

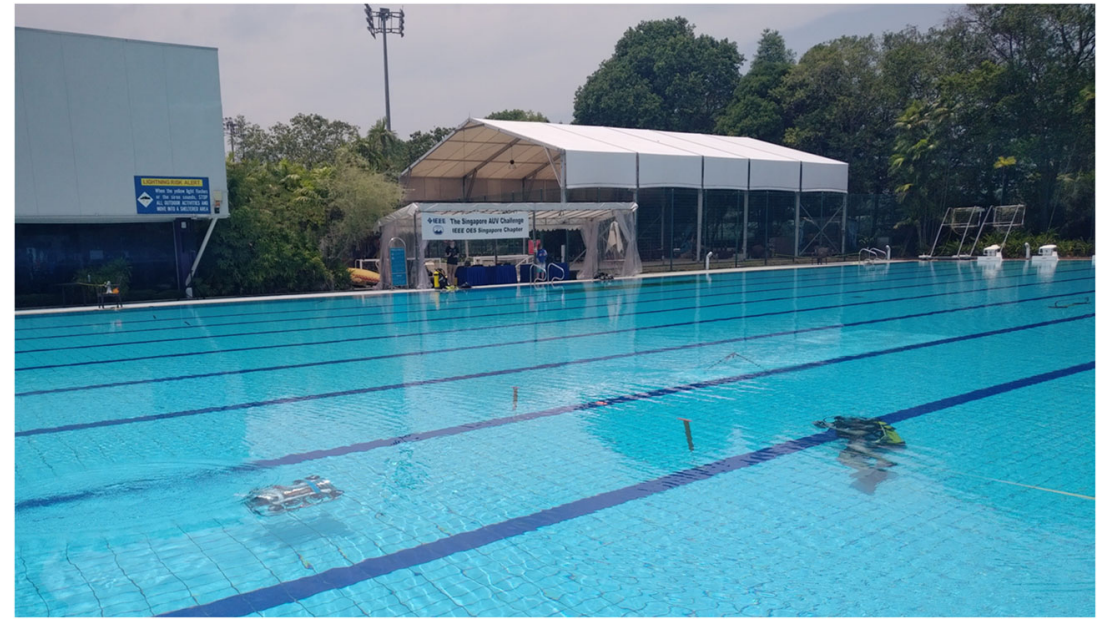

\section{SAUVC}

SAUVC [25, 45] includes a 1-day workshop/discussion immediately after the competition is finished (the day after the finals). In this way, teams can participate in the community building process without the need for additional travels. SAUVC has become increasingly popular in Asia in only 7 years with more than 70 teams attending in 2019 coming from 16 countries. Similarly, to RoboSub and SAUC-E, a minimum number of team members must be students ( $50 \%$ in this case). Tasks include passing through a gate, navigating on a straight line, finding an acoustic pinger, dropping and picking objects. This competition has an interesting particularity. While Robosub or SAUC-E attributed time bonus for completing all tasks before the end of the time slot, SAUVC goes beyond this and chooses the finalists by the time they take to pass the gate. Thus, this stimulates teams to navigate on a straight line as fast as they can until the gate but making sure that their controllers do not overshoot and that the vehicle can keep a stable direction.

The competition takes place in a swimming pool (seen in Fig. 5), and its goal is mainly educational. SAUVC works as the perfect training ground for teams to develop and improve their vehicles year after year.

For the 2020 edition (postponed due to COVID-19), the organisers planned to have an obstacle in between the starting point and the gate which will significantly increase the difficulty and require teams to perform obstacle avoidance.

\section{Conclusions}

The world of marine robotics competitions is broad and diverse. From the inception of the first competition in the late 1990s, marine robotics competitions and challenges proliferated through the world encompassing almost all continents and all domains related to the sea. While initial competitions focused on students and had mainly an educational role, in later years, competitions introduced Grand Challenge--style objectives and features. Thus, the community has recognised the value of competitions also as an effective means for advancing the state of the art. This is especially true for AUV and ASV technologies that, despite their maturing in the last years, are still less mature than ROVs that have worked underwater for more than 50 years. Problems like autonomous underwater manipulation, autonomy and deep water navigation are not yet fully solved for AUVs. Competitions can push the state of the art in these topics promoting innovation, at the same time fostering the technology transfer between research and industry. There have been several cases of companies spinning-off universities after some years of experience in competitions. New research teams have entered marine robotics by having access to standard platforms (e.g. used in euRathlon or RobotX Challenge) [49]. The standard platforms' development has been facilitated as well by the competitions in a virtuous circle where companies get feedback from beta users (like student teams) and improve their products with ideas coming from the research community.

In competitions targeting at more experienced participants, a recent common trend is to push for adaptive mission planning and cooperative autonomy for multi-domain systems. Organisers have proposed tasks where pre-programmed missions are not sufficient and autonomous decision-making is necessary for success (e.g. in RobotX, ERL Emergency). They have also designed tasks that require cooperation between multi-domain robots (e.g. surface and underwater robots in euRathlon, ERL Emergency and RobotX). This task design is representative of the importance that autonomy has today and will have in the near future when advanced autonomous multi-robot underwater systems will operate at sea. The importance of autonomy and AI has also been stressed with the introduction of virtual competitions. Virtual competitions move the attention from the robot hardware to the autonomy and perception, allowing research teams not experienced in marine robotics to test and tune their algorithms for the marine domain. 
In the future, these trends are expected to continue along with the harmonisation among several competitions and the fostering of a marine robotics competitions community through the MASC2 committee. In parallel, purely studentbased competitions should continue to play their fundamental educational role and keep preparing students to real-life challenges as either professionals or members of teams participating in moon-shot challenges like the Shell Ocean Discovery XPRIZE.

Funding They have received grants from the European Commission (Under euRathlon FP7, RockEU2 FP7SciRoc H2020 project.)

\section{Compliance with Ethical Standards}

Conflict of Interest Dr. Ferri and Dr. Ferreira have been involved since 2013 in the organisation of different competitions. In particular, they have been the organisers of SAUC-E, euRathlon and of some editions of ERL Emergency. Finally, they are both members of MASC2 committee.

Human and Animal Rights and Informed Consent This article does not contain any studies with human or animal subjects performed by any of the authors.

\section{References}

Papers of particular interest, published recently, have been highlighted as:

- Of importance

• Of major importance

1. RoboCup website [Online] Available: https://www.robocup.org/. Accessed 10 May 2020.

2. FIRST LEGO League website [Online] Available: https:// firstlegoleague.org/. Accessed 10 May 2020.

3. DARPA Grand Challenge website [Online] Available: http://www. grandchallenge.org/. Accessed 10 May 2020.

4. DARPA Robotics Challenge archive website [Online] Available: https://archive.darpa.mil/roboticschallenge/. Accessed 12 May 2020.

5. Mohamed Bin Zayed International Robotics Challenge website [Online] Available http://www.mbzirc.com/. Accessed 13 May 2020.

6. Ribeiro A, Lopes G. Learning robotics: a review. Curr Robot Rep. 2020;1:1-11. https://doi.org/10.1007/s43154-020-00002-9.

7. RoboSub website. [Online] Available: https://robosub.org/. Accessed 13 May 2020.

8. MATE ROV Competition website [Online] Available: https:// www.materovcompetition.org/. Accessed 13 May 2020.

9. The Microtransat Challenge website [Online] Available: https:// www.microtransat.org/. Accessed 13 May 2020.

10. SailBot website [Online] Available: https://www.sailbot.org/. Accessed 14 May 2020.

11. Student AUV Challenge - Europe (SAUC-E) website [Online] Available: https://www.sauc-europe.org. Accessed 15 May 2020.

12. Matsuda T. Underwater Robot Convention in JAMSTEC 2019 IEEE OES Beacon Newsletter. 2019;8(3). Available: https:// ieeeoes.org/oes-beacon/september-2019-oes-beacon/underwaterrobot-convention-in-jamstec-2019/. Accessed 13 May 2020.
13. Arima M, Ishii K, Ura T, Maki T, Kondo H. Evolution and prospects of underwater robot competition in Japan. Oceans. 2015 Genova, Genoa:1-6. https://doi.org/10.1109/OCEANS-Genova. 2015.7271559. Accessed 12 May 2020.

14. RoboBoat website. [Online] Available: https://roboboat.org/. Accessed 13 May 2020.

15. World Robotic Sailing Championship website [Online] Available: https://roboticsailing.org/. Accessed 13 May 2020.

16. Le Bars F, Jaulin L. The world robotic sailing championship, a competition to stimulate the development of autonomous sailboats. Oceans. 2015 - Genova:1-5. https://doi.org/10.1109/OCEANSGenova.2015.7271767.

17. SeaPerch website [Online] Available: https://www.seaperch.org/. Accessed 15 May 2020.

18. Nelson SG, Cooper KB, Djapic V. SeaPerch: How a start-up handson robotics activity grew into a national program. Oceans. $2015-$ Genova:1-3. https://doi.org/10.1109/OCEANS-Genova.2015. 7271419.

19. Groark L, Cooper K, Davidson D. The SeaPerch evolution: from grassroots to a global community, 2019 IEEE Integrated STEM Education Conference (ISEC), Princeton, NJ, USA, 2019, pp. 274-80. https://doi.org/10.1109/ISECon.2019.8882075.

20. Indian National Competition on Students Autonomous Underwater Vehicle (SAVe) website [Online] Available https://www.niot.res. in/SAVe/. Accessed 15 May 2020.

21. Atmanand MA, Venkatesan R, Sundar R, Kadiyam J. Indian national student AUV competition: a success story. Oceans. $2015-$ Genova:1-6. https://doi.org/10.1109/OCEANS-Genova.2015. 7271698.

22. R. Venkatesan, R. Sundar, J. Kadiyam, M. A. Atmanand. A success story of Indian National Student Autonomous Underwater Vehicle Competition (2011-2017); 2018. [Online] Available: http://www. oceansociety.in/wp-content/uploads/2019/06/SAVe-Report_2017. pdf. Accessed 20 May 2020.

23.• Ferri G, Ferreira F, Djapic V, Petillot Y, Palau M, Winfield A. The euRathlon 2015 Grand Challenge: the first outdoor multi-domain search and rescue robotics competition - a marine perspective. Mar Technol Soc J. 2016;50(4):81-97. This paper describes the euRathlon 2015 Grand Challenge from a marine robot perspective. The importance of the competition was that for the first time a cooperative multi-domain (air, ground, sea) robotics team was challenged in a realistic search and rescue scenario inspired by the Fukushima 2011 accident. The paper describes the tasks and how the cooperation of the marine robots with the other domain was handled.

24. OI China Underwater Robot Competition website [Online] Available: http://www.oichina.com.cn/en/Conference-Activities/ Underwater-Robot-Competition/. Accessed 20 May 2020.

25. Singapore AUV Challenge website [Online] Available https:// sauvc.org/. Accessed 20 May 2020.

26. Pallayil V, Chitre M, Kalyan B, Suman S, Koay TB, et al. The Singapore Autonomous Underwater Vehicle Challenge (SAUVC): an effort to engage and expose young engineers to challenges of underwater robotics. Oceans. 2015 - Genova:1-9. https:// doi.org/10.1109/OCEANS-Genova.2015.7271250.

27. 2020 RobotX Challenge website. [Online] Available: https:// robotx.org/programs/2020-robotx-challenge/. Accessed 20 May 2020.

28. Shell Ocean Discovery XPRIZE website [Online] Available: https://oceandiscovery.xprize.org. Accessed 20 May 2020.

$29 . \bullet$ Rosen J. Seafloor mappers to compete for XPRIZE. Science. 2018;362(6414):507-8. https://doi.org/10.1126/science.362.6414. 507. This paper describes the different approaches of the teams' participant in the Shell XPRIZE Grand Challenge. The paper describes the new ideas and efforts put by toprank institutions for improving their robots, showing how a 
Grand Challenge in the marine domain can push the state of the art.

30. European Robotics League Emergency Robots website [Online] Available: https://www.eu-robotics.net/robotics_league/erlemergency/about/index.html. Accessed 23 May 2020.

31. 2019 Virtual RobotX Competition website. [Online]. Available: https://robotx.org/programs/2019-virtual-robotx-competition/. Accessed 23 May 2020.

32. Metrological Evaluation and Testing of Robots in International Competitions (METRICS) EU Project website [Online] Available: https://metricsproject.eu/. Accessed 23 May 2020.

33. Jacoff A, Saidi K, Von Loewenfeldt R, Koibuchi Y. Development of standard test methods for evaluation of ROV/AUV performance for emergency response applications. Oceans - MTS/IEEE Washington. 2015:1-10. https://doi.org/10.23919/OCEANS.2015. 7404629.

34. Ferreira F, Ferri G, Petillot Y, Liu X, Franco MP, Matteucci M, et al. Scoring robotic competitions: balancing judging promptness and meaningful performance evaluation, 2018 IEEE International Conference on Autonomous Robot Systems and Competitions (ICARSC), Torres Vedras, 2018, pp. 179-85. https://doi.org/10. 1109/ICARSC.2018.8374180.

35. Lundquist E, Djapic V. SAUC-E offers student teams realistic challenge: Maritime Reporter and Marine News magazine; 2012. https://www.marinelink.com/news/realistic-challenge 342323

36. Ferri G, Ferreira F, Djapic V. Boosting the talent of new generations of marine engineers through robotics competitions in realistic environments: the SAUC-E and euRathlon experience. Oceans. 2015 Genova:1-6. https://doi.org/10.1109/OCEANS-Genova.2015. 7271509.

37. Ferri G, Ferreira F, Djapic V. Fostering marine robotics through competitions: from SAUC-E to ERL Emergency. OCEANS 2018 MTS/IEEE Charleston. 2018:1-7. https://doi.org/10.1109/ OCEANS.2018.8604580.

38. BeeX Autonomous Systems [Online] Available: https://beex.sg/. Accessed 23 May 2020

39. Iqua Robotics [Online] Available: http://iquarobotics.com/. Accessed 1 June 2020.

40. W. Kirkwood, T. Curtin. Student autonomous maritime vehicle competitions: international coordination and initial benchmarking. 2018. [On-line]. Available: https://earthzine.org/studentautonomous-maritime-vehicle-competitions-internationalcoordination-and-initial-benchmarking/. Accessed 1 June 2020.

41. Ferri G, Ferreira F, Djapic V. Multi-domain robotics competitions: the CMRE experience from SAUC-E to the European Robotics League Emergency Robots. Oceans. 2017 - Aberdeen:1-7. https://doi.org/10.1109/OCEANSE.2017.8084767.
42. van der Meer AJ, Caccavale F, Eredics G. The EuRoC project: motivations and design of the challenges. In: Caccavale F, Ott C, Winkler B, Taylor Z, editors. Bringing innovative robotic technologies from research labs to industrial end-users. Springer Tracts in Advanced Robotics. Cham: Springer; 2020. p. 136.

43.• Bingham B, Agüero C, McCarrin M, Klamo J, Malia J, Allen K, et al. Toward Maritime robotic simulation in gazebo. OCEANS MTS/IEEE SEATTLE. 2019:1-10. https://doi.org/10.23919/ OCEANS40490.2019.8962724. This paper describes the simulation framework used for the RobotX virtual challenge. RobotX virtual challenge is an example of the new generation of virtual marine competitions. In the future, they will help to prepare participants for physical events and will attract researchers from other communties to test their algorithms in the marine domain.

44. Transatlantic crossing 2018. [Online] Available: http://sailbuoy.no/ news-2/64-transatlantic-crossing. Accessed 1 June 2020.

45. Harold Tay KT, Pallayil V. The Singapore AUV Challenge (SAUVC) 2016. IEEE OES Beacon Newsletter. 2016;5(2).

46. Franchi M, Fanelli F, Bianchi M, Ridolfi A, Allotta B. Underwater robotics competitions: the European Robotics League emergency robots experience with FeelHippo AUV. Front Robot AI. 2020;7. https://doi.org/10.3389/frobt.2020.00003. This study describes the experience of the University of Florence team in SAUC-E, euRathlon and ERL competitions. It demonstrates the advancements the team had over the years in terms of autonomous navigation, sensing and mission management. This demonstrates how participating yearly to competitions can help in forming a mature research group in marine engineering.

47. Winfield AFT, Franco MP, Brueggemann B, Castro A, Limon MC, et al. euRathlon 2015: a multi-domain multi-robot Grand Challenge for search and rescue robots. In: Alboul L, Damian D, Aitken J, editors. Towards Autonomous Robotic Systems. TAROS, Lecture notes in computer science. Cham: Springer; 2016. p. 9716.

48. Marine Advanced Robotics website [Online] Available: http:// www.wam-v.com/. Accessed 1 June 2020.

49. Sütő B, Dóczi R, Kalló J, Takács B, Várkonyi TA, Haidegger T, et al. HSV color space based buoy detection module for autonomous underwater vehicles, 2015 16th IEEE International Symposium on Computational Intelligence and Informatics (CINTI), Budapest, 2015; pp. 329-32. https://doi.org/10.1109/CINTI.2015.7382944.

Publisher's Note Springer Nature remains neutral with regard to jurisdictional claims in published maps and institutional affiliations. 